\title{
Indicativo de contaminação ambiental por metais pesados em aterro sanitário
}

\author{
Indicative of environmental pollution by heavy metals in landfill \\ Pedro Daniel da Cunha Kemerich', Carlos Eduardo Balestrin Flores², Willian Fernando de Borba ${ }^{3}$, \\ Ademir Eloi Gerhardt ${ }^{4}$, Bruno Acosta Flores ${ }^{4}$, Alexandre Couto Rodrigues ${ }^{4}$, Guilherme Barros ${ }^{4}$ \\ ' Coordenador do Curso de Engenharia Ambiental da Universidade Federal de Santa Maria/CESNORS, Frederico Westphalen, Brasil. \\ ${ }^{2}$ Universidade Federal de Santa Maria, Santa Maria, Brasil. \\ 3 Técnico em Agropecuária, Aluno de Graduação do Curso de Engenharia Ambiental, Universidade Federal de Santa Maria, Santa Maria, \\ Brasil. \\ ${ }^{4}$ Laboratório de Planejamento e Monitoramento Ambiental - LPMA/UFSM, Curso de Engenharia Ambiental da Universidade Federal de \\ Santa Maria/CESNORS, Frederico Westphalen, Brasil.
}

\begin{abstract}
Resumo
O chorume é um liquido escuro que contém altas concentrações de compostos orgânicos e inorgânicos. Esse líquido pode conter metais pesados, sólidos suspensos e compostos orgânicos originados da degradação de substâncias que são metabolizadas, como carboidratos, proteínas e gorduras. Em virtude do local onde se encontra, poderá atingir e contaminar o solo e os recursos hídricos superficiais e subterrâneos, pondo em risco a população que vive nas proximidades da área. O presente trabalho teve como objetivo analisar as concentrações dos metais pesados bário, cobre e cromo, em solo ocupado por aterro sanitário. Para coleta do solo foram realizadas tradagens em 10 diferentes pontos e profundidades. Para determinação dos metais foi utilizado a técnica de Fluorescência de Raios-X por Energia dispersiva, e, com auxilio do software Surfer 10, foram especializados os dados gerando-se os cartogramas. Todos os metais citados no presente trabalho indicam contaminação do solo em alguns pontos e profundidades, destacando-se o ponto 8 a uma cota de 538,94 m, obtendo concentrações de Bário, Cobre e Cromo indicando relação do fluxo superficial e sub superficial da água com contaminação por estes elementos. Com os resultados obtidos pode-se constatar o potencial de contaminação por metais em solo ocupado pelo Aterro Sanitário.
\end{abstract}

Palavras-chave: Aquífero subterrâneo; Lixiviado; Resolução CONAMA 420/2009a

\begin{abstract}
The manure is a dark liquid, which contains high concentrations of organic and inorganic compounds. This fluid can contain heavy metals, suspended solids and organic compounds derived from the degradation of substances that are metabolized as carbohydrates, proteins and fats. By virtue of the place where you can reach and contaminate soil and surface and underground water resources, threatening the population living near the area. This study aimed to analyze the concentrations of heavy metals barium, copper and chromium in soil occupied by the landfill. To collect soil auger were performed on 10 different sites and depths. To determine the metal has been used the technique of fluorescence X-ray Energy Dispersive and with the aid of specialized software 10 were Surfer generating the data to the maps. All metals cited in this study indicate soil contamination at some sites and depths, highlighting the point 8 a share of $538.94 \mathrm{~m}$, obtaining concentrations of barium, copper and chromium indicating relation of the surface flow and sub-surface water contaminated by these elements, with the results obtained it can be seen the potential of metal contamination in soil displaced by landfill.
\end{abstract}

Keywords: Groundwater aquifer; Manure; CONAMA Resolution 420/2009 


\section{INTRODUÇ̃̃o}

Atualmente, uma das grandes preocupações ambientais está relacionada aos resíduos sólidos gerados pela sociedade moderna e consumista. Com rápido processo industrial, aliada ao crescimento da população e à consequente demanda por bens de consumo, o homem tem produzido quantidades significativas de resíduos, que acabam sendo constituídos de uma mistura muito complexa e de natureza diversa, cujos principais constituintes são: material orgânico, papel, vidro, plástico, dentre outros matérias pesados que possam acarretar na poluição do solo e de águas superficiais e subterrâneas.

Segundo ALENCAR (2005), a questão ambiental está se tornando um tema relevante que precisa ser discutido em toda a extensão da sociedade civil. Além da discussão, também se faz necessário que sejam empreendidas ações em vários níveis, tais como: individual, empresarial, institucional, governamental, não governamental, local, regional, nacional e internacional.

O aterro sanitário é a forma mais econômica e segura ambientalmente de disposição de resíduos sólidos urbanos. Consiste na utilização de métodos de engenharia para confinar os dejetos na menor área possível, reduzi-los a um menor volume e cobri-los, frequentemente, com uma camada de terra (GARCILASSO et al., 2010).

Para HIRATA (1993), a construção de aterros de resíduos sólidos tem que obedecer a normas mínimas da Associação Brasileira de Normas Técnicas (ABNT). A obra deverá ser bem localizada em relação aos aquíferos existentes. Estudos hidro geológicos prévios serão necessários e, quando da construção, deverá ser exigida uma camada impermeável inferior de argila de 0,6 a $1,5 \mathrm{~m}$ de espessura e um recobrimento diário de 0,1 a 0,3m de material compactado. Algumas vezes, será necessária a colocação de camadas de material sintético (liner), de grande resistência mecânica e química, para garantir a completa vedação hidráulica do empreendimento. Naturalmente, os estratos da zona não saturada deverão ser de material de baixa permeabilidade. Um cuidado especial precisará ser dado aos resíduos recebidos, especificando origem e composição mínima. Drenos superficiais serão necessários para diminuir o ingresso de águas de chuva por escorrimento superficial, no núcleo do aterro.

TARTARI (2005) relata que a disposição de resíduos sem os devidos cuidados pode gerar a proliferação de agentes patogênicos, acarretar na poluição do solo, do ar e de recursos hídricos, através da migração dos elementos constituintes do chorume e de gases produzidos através do processo de degradação da matéria orgânica desses depósitos.

MORAIS et al. (2006) dizem que o chorume é um resíduo líquido de elevada carga orgânica e forte coloração, produzido pela decomposição química e microbiológica dos resíduos sólidos. A sua composição química apresenta grande variabilidade, uma vez que, além de depender da natureza dos resíduos depositados, da forma de disposição, do manejo e da idade do composto, é extremamente influenciada por fatores climáticos, dentre os quais se podem destacar a quantidade de chuva e a temperatura.

Com relação ao tema exposto, o presente trabalho tem como objetivo especializar as concentrações totais de Bário, Cobre e Cromo em área ocupada por aterro sanitário, utilizando a técnica de Espectrometria de Fluorescência de Raios-X por Energia Dispersiva.

\section{MATERIAIS E MÉTODOS}

\section{I Caracterização da área de estudo}

O município de Seberi está situado no noroeste do estado do Rio Grande do Sul, Brasil, na latitude $27^{\circ}$ $28^{\prime} 4^{\prime \prime}$ S e longitude $53^{\circ} 24^{\prime} 09^{\prime \prime}$, com altitude de 546 $\mathrm{m}$ do nível do mar, abrangendo uma área de $301 \mathrm{~km}^{2}$ e com população de 11098 habitantes, sendo o mesmo pertencente à bacia hidrográfica do Rio Uruguai, com clima subtropical úmido (IBGE, 2009). O CIGRES (Consórcio Intermunicipal de Gestão de Resíduos Sólidos) está localizado na BR 386, km 43, Distrito de Osvaldo Cruz, pertencente à cidade de Seberi - RS, é um consórcio entre 30 municípios e uma área total $7,77 \mathrm{ha}$, com abrangência de $4.88360 \mathrm{~km} 2$, atendendo cerca de 162 mil habitantes, recebendo entorno de 1200 toneladas de resíduos sólidos urbanos mensalmente.

\subsection{Localização dos pontos de amostragem e coleta de amostras}

A metodologia usada para a coleta e escolha dos pontos de amostragem foi a mesma utilizada por KEMERICH et al. (2012), onde as tradagens para coleta das amostras foi realizada em função da topografia existente no terreno e do fluxo preferencial de água superficial, determinado com o auxílio do software Surfer 10 da Golden Software, utilizando-se o método de interpolação matemática Krigagem (figura 1). Foram considerados 10 pontos de coleta, sendo que estes receberam nomenclatura variando de P1a P10, sendo que $\mathrm{P} 1$ o ponto de maior cota $(545,42 \mathrm{~m})$, considerado como ponto controle, e P10 o de menor cota topográfica $(518 \mathrm{~m})$.

Para a coleta das amostras foi utilizado um trado manual Sonda Terra de $3 \mathrm{~m}$ de comprimento (figura 2a). Cada amostra coletada foi armazenada em sacos plásticos e recebeu identificação correspondendo à localização do ponto de amostragem e a profundidade da coleta. Nos 10 pontos analisados foram coletadas amostras a cada $50 \mathrm{~cm}$ de profundidade, iniciando-se 


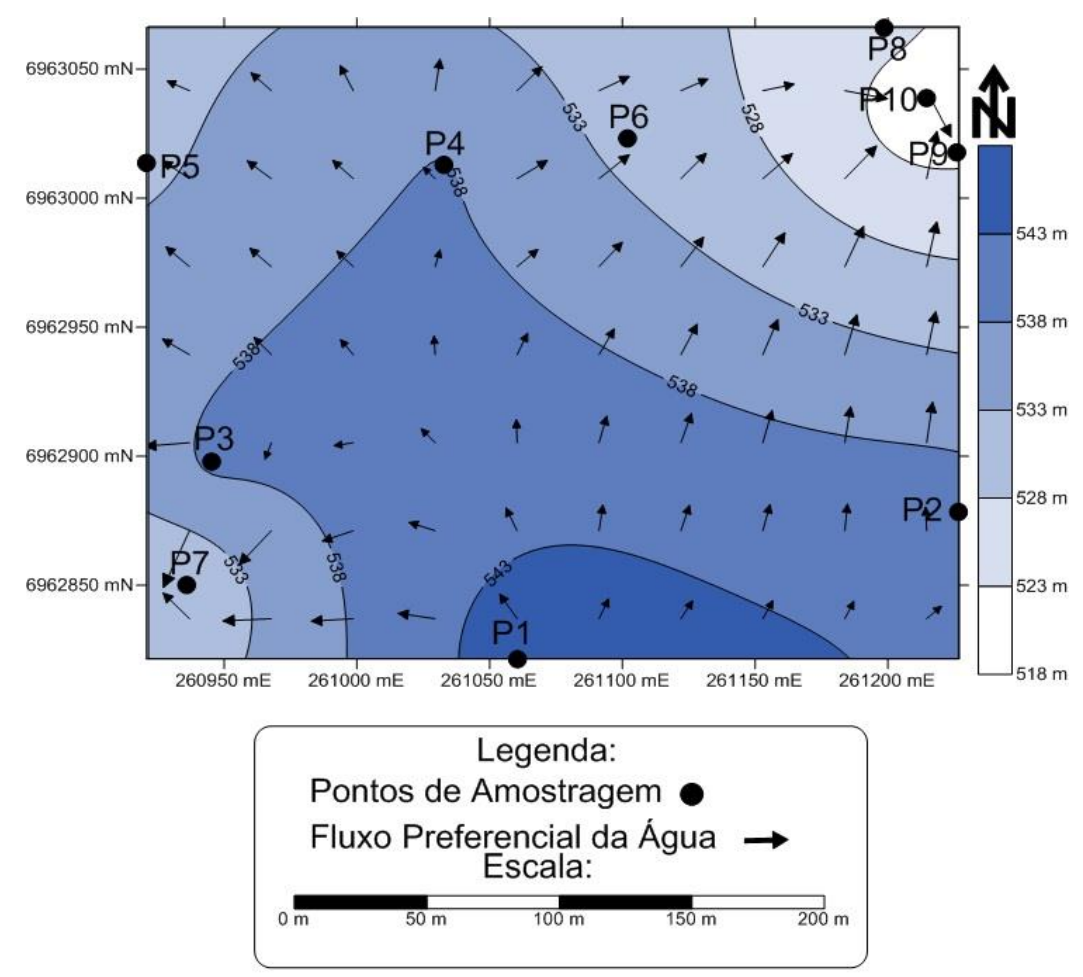

Figura 1. Área de estudo no município de Seberi - RS, com linhas de fluxo e pontos de amostragem.

com a amostra superficial $(0 \mathrm{~cm})$ até $300 \mathrm{~cm}$, totalizado 7 amostras por ponto (figura $2 b$ ). Para evitar alterações nos resultados, o trado era lavado com água destilada, conforme a figura $2 \mathrm{c}$.

\subsection{Preparo de amostras e determinação de metais}

Foram pesadas $20 \mathrm{~g}$ de solo e encaminhadas para a secagem em Estufa de Esterilização e Secagem, utilizando vidraria básica de laboratório (becker $50 \mathrm{~mL}$ ) para sua deposição. $\mathrm{O}$ processo de secagem ocorreu à temperatura de $105^{\circ} \mathrm{C}$ por duas horas.

Após o quarteamento e a secagem em estufa as amostras foram moídas manualmente em Gral com Pistilo, objetivando reduzir ao máximo a granulometria da amostra reduzindo os devios do feixe de Raios X, provenientes do aparelho (Shimadzu Energy Dispersion Fluorescence X-ray Spectrometer Rany, Serie EDX720) e enfluenciando na eficiência das determinações.

As amostras de solo foram postas em tubos cilíndricos com diâmetro de $2 \mathrm{~mm}$ cobertos com um plástico chamado mylar, então encaminhadas para a análise. Este proscedimento aglomera as partículas tornando-as um aglomerado cerâmico cujo resultado analítico reflete-se num padrão ideal para análise do EDXRF, sendo um método rápido e indireto.

De uma forma, em geral as análises quantitativas por EDXRF são realizadas pelo método da curva de calibração, obtida por vários padrões. No entanto, para algumas é difícil obter padrões certificados, com matriz
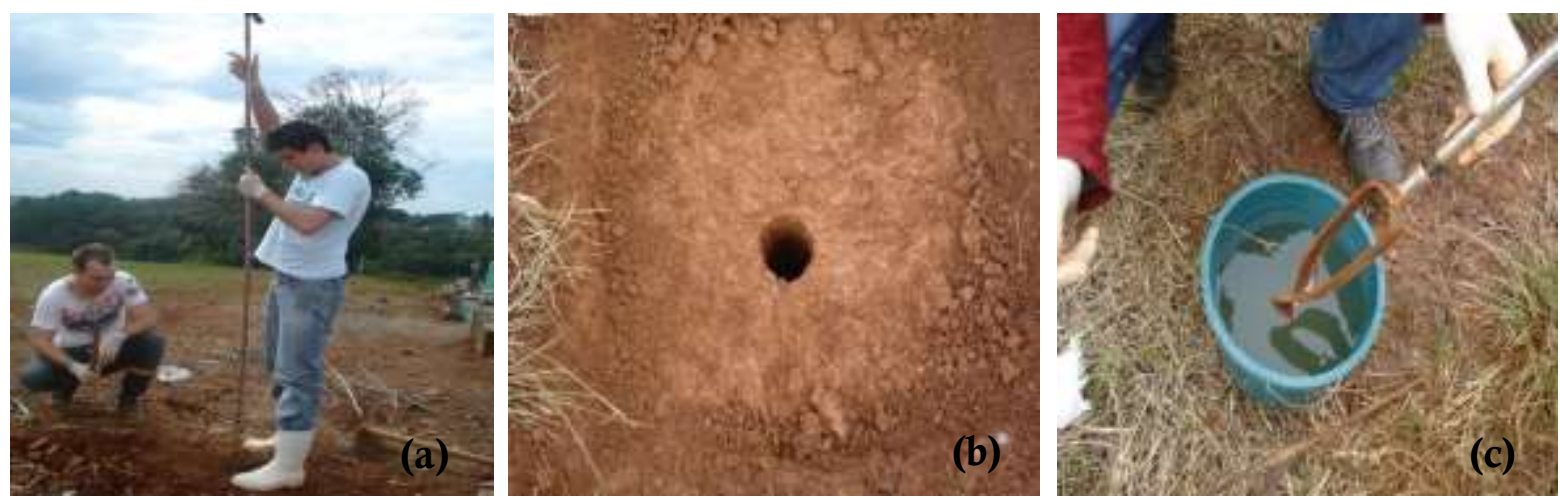

Figura 2. Tradagem efetuada na área de estudo, utilizando trado manual Sonda terra $3 \mathrm{~m}$ (a), local de tradagem (b) e limpeza do trado em água destilada (c), Seberi - RS, 2011. 
Tabela 1. Valores de referência para solos.

\begin{tabular}{|c|c|}
\hline Bário & 150 \\
\hline Cobre & 60 \\
\hline Cromo & 75 \\
\hline
\end{tabular}

Fonte: Adaptado de CONAMA N²020/2009

semelhante às amostras. As análises foram realizadas utilizando um Espectrômetro de Fluorescência de Raios-X por Energia Dispersiva, do modelo Shimadzu EDX-720, onde as condições de operação seguiram as usadas por PATACA et al. (2005), com tensão do tubo de $15 \mathrm{keV}$ ( $\mathrm{Na}$ a Sc) e $50 \mathrm{keV}$ ( $\mathrm{Ti} \mathrm{a} \mathrm{U}$ ) com corrente no tubo $184 \mu \mathrm{A}$ e $25 \mu \mathrm{A}$, respectivamente, colimador de 10 $\mathrm{mm}$, tempo morto do detector de $40 \%$ e $39 \%$, sob vácuo e detector de $\mathrm{Si}(\mathrm{Li})$, refrigerado com nitrogênio líquido, porém com tempo real de integração de 200 segundos, diferentemente do utilizado por WASTOWSKI et al. (2010), que utilizou $300 \mathrm{~s}$. O método analítico usado é denominado método dos Parâmetros Fundamentais (FP), este método permite a obtenção da curva de sensibilidade do equipamento para cada elemento de interesse, quando uma amostra de composição química conhecida é submetida a parâmetros instrumentais bem definidos, a curva de sensibilidade do equipamento relaciona a intensidade fluorescente teórica calculada e a medida para cada elemento (BONA et al., 2007; WASTOWSKI et al., 2010).

Os valores de referência para solos estão apresentados na tabela 1 .

Foram determinadas as concentrações totais dos metais: Bário (Ba), Cobre $(\mathrm{Cu})$, Cromo $(\mathrm{Cr})$, que possuem valor de referência propostos pela CONAMA $n^{\circ} 420 / 2009$, na qual rege sobre critérios e valores orientadores de qualidade do solo quanto à presença de substâncias químicas e estabelece diretrizes para o gerenciamento ambiental de áreas contaminadas em decorrência de atividades antrópicas.

\section{RESULTADOS E DISCUSSÃO}

O quadro 1 ilustra a concentração dos metais em todos os pontos e profundidades analisados.

\section{I Bário $(\mathrm{Ba})$}

CUNHA \& MACHADO (2004) afirmam que as concentrações de bário entre 550 a 600 mg são fatais ao homem, causa bloqueio nervoso ou aumento da pressão sanguínea por vaso constrição
Quadro 1. Concentração dos metais nos pontos de amostragem.

\begin{tabular}{|c|c|c|c|c|c|}
\hline & \multirow{2}{*}{$\begin{array}{c}\text { Profundidade } \\
(\mathrm{cm})\end{array}$} & \multicolumn{3}{|c|}{$\begin{array}{c}\text { Concentração dos metais } \\
\left(\mathrm{mg} \mathrm{kg}^{-1}\right)\end{array}$} \\
\hline & & & $\mathrm{Ba}$ & $\mathrm{Cu}$ & $\mathrm{Cr}$ \\
\hline \multirow{35}{*}{ 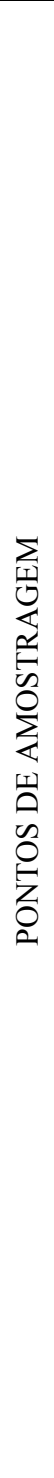 } & \multirow{7}{*}{1} & 0 & $<$ L.D $^{*}$ & 570,00 & 158,97 \\
\hline & & $0-50$ & $<$ L.D & 623,40 & 209,48 \\
\hline & & $50-100$ & 5951,75 & 556,67 & 175,55 \\
\hline & & $100-150$ & 9546,39 & 626,96 & 131,02 \\
\hline & & $150-200$ & $<$ L.D & 559,65 & 134,59 \\
\hline & & $200-250$ & 5852,65 & 456,55 & 178,46 \\
\hline & & $250-300$ & 6367,89 & 623,46 & 157,35 \\
\hline & \multirow{7}{*}{2} & 0 & 4780,09 & 395,38 & 92,59 \\
\hline & & $0-50$ & 3776,95 & 416,40 & 101,12 \\
\hline & & $50-100$ & 2404,20 & 319,31 & 86,82 \\
\hline & & $100-150$ & 8549,93 & 410,39 & 85,68 \\
\hline & & $150-200$ & 4655 & 445,09 & 90,51 \\
\hline & & $200-250$ & $<$ L.D & 491,26 & 166,37 \\
\hline & & $250-300$ & $<$ L.D & 474,32 & 136,64 \\
\hline & \multirow{7}{*}{3} & 0 & 2769,88 & 269,08 & 69,08 \\
\hline & & $0-50$ & 3423,83 & 274,93 & 79,23 \\
\hline & & $50-100$ & 6015,18 & 290,18 & 66,89 \\
\hline & & $100-150$ & 4991,50 & 304,87 & 104,52 \\
\hline & & $150-200$ & 2998,19 & 214,79 & 72,99 \\
\hline & & $200-250$ & 5037,25 & 312,64 & 78,64 \\
\hline & & $250-300$ & 3145,97 & 395,87 & 80,57 \\
\hline & \multirow{7}{*}{4} & 0 & 1782,10 & 257,88 & 71,74 \\
\hline & & $0-50$ & 5270,33 & 336,83 & 50,36 \\
\hline & & $50-100$ & 3391,87 & 253,89 & 76,36 \\
\hline & & $100-150$ & 3024,92 & 236,15 & 86,87 \\
\hline & & $150-200$ & 4265,49 & 279,53 & 77,36 \\
\hline & & $200-250$ & 6602,58 & 312,96 & 74,70 \\
\hline & & $250-300$ & 4179,50 & 246,76 & 65,88 \\
\hline & \multirow{7}{*}{5} & 0 & 6575,22 & 328,08 & 60,80 \\
\hline & & $0-50$ & 6521,40 & 279,96 & 56,24 \\
\hline & & $50-100$ & 6336,14 & 300,98 & 59,07 \\
\hline & & $100-150$ & 5476,19 & 272,93 & 71,43 \\
\hline & & $150-200$ & 6961,57 & 440,96 & 92,06 \\
\hline & & $200-250$ & 6471,07 & 355,78 & 82,61 \\
\hline & & $250-300$ & 8909,07 & 428,47 & 79,02 \\
\hline
\end{tabular}

* < L.D.: Menor que o Limite de Detecção do aparelho Shimadzu EDX-720

Continua... 
Quadro 1. Continuação...

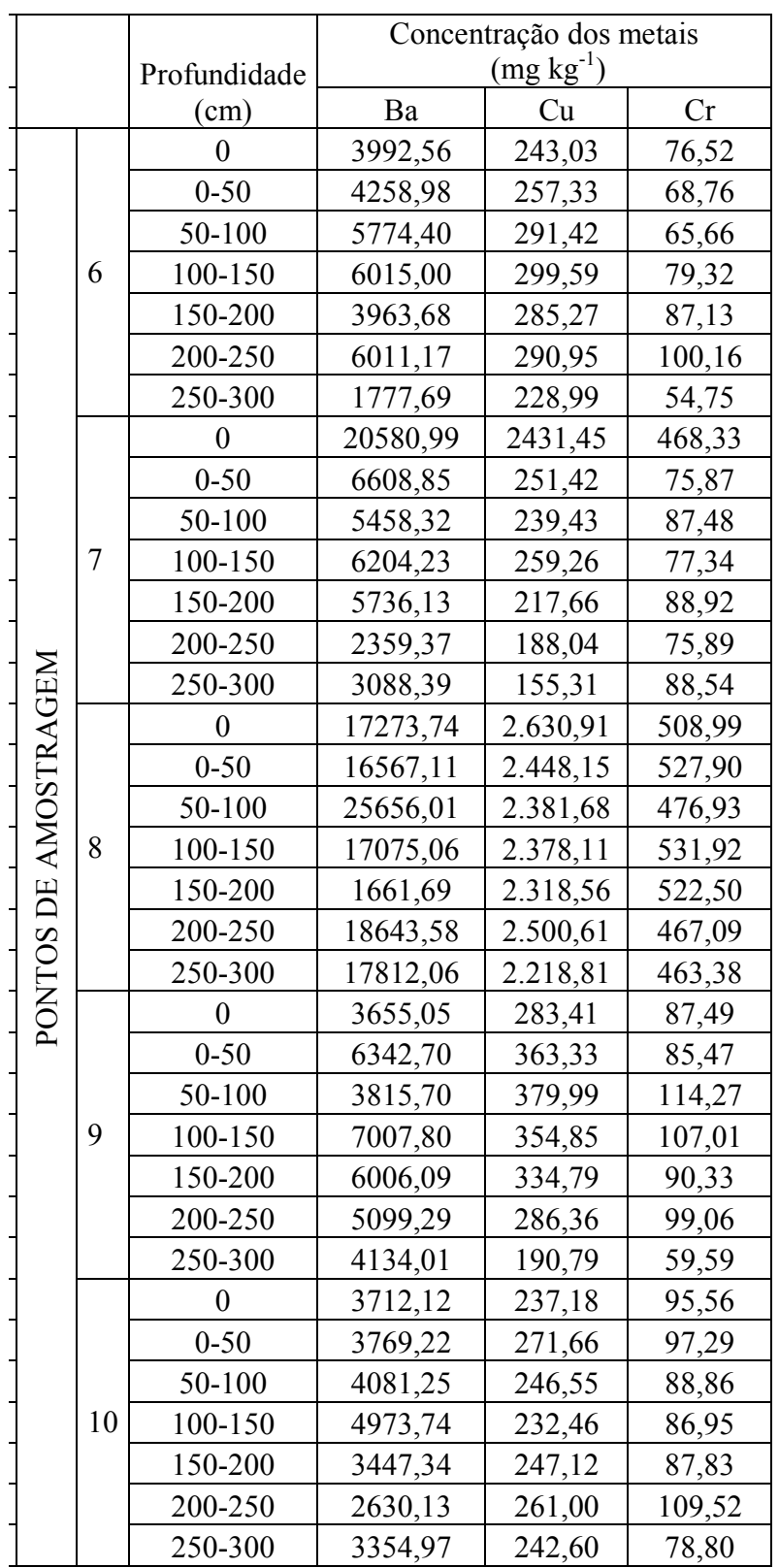

* < L.D.: Menor que o Limite de Detecção do aparelho Shimadzu EDX-720

A figura 3 ilustra as diferentes concentrações de $\mathrm{Ba}$ total, na área ocupada pelo aterro sanitário, nos pontos $\mathrm{P} 1 \mathrm{a}$ P10, nas profundidades $0,50,100 \mathrm{e}$ $150 \mathrm{~cm}$. Como pode ser observado na figura 3 , a concentração de $\mathrm{Ba}$ em todos os pontos de amostragem ultrapassaram os valores médios permitidos (VMP) pelo CONAMA $N^{\circ} 420 / 2009$, que estabelece valor limite de bário no solo de $150 \mathrm{mg} \mathrm{kg}{ }^{-1}$, com exceção do ponto $\mathrm{P} 1$, nas profundidades de 0 e $50 \mathrm{~cm}$, onde a concentração foi menor que o limite de detecção (L.D.) da técnica EDXRF.

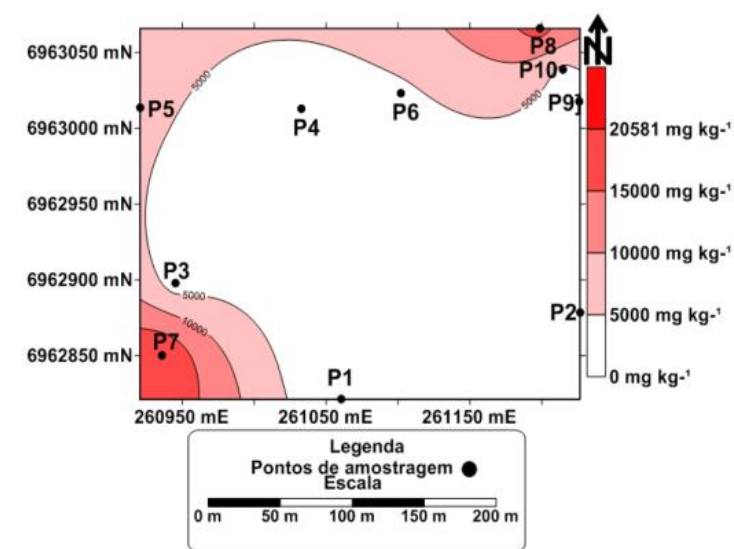

(a)

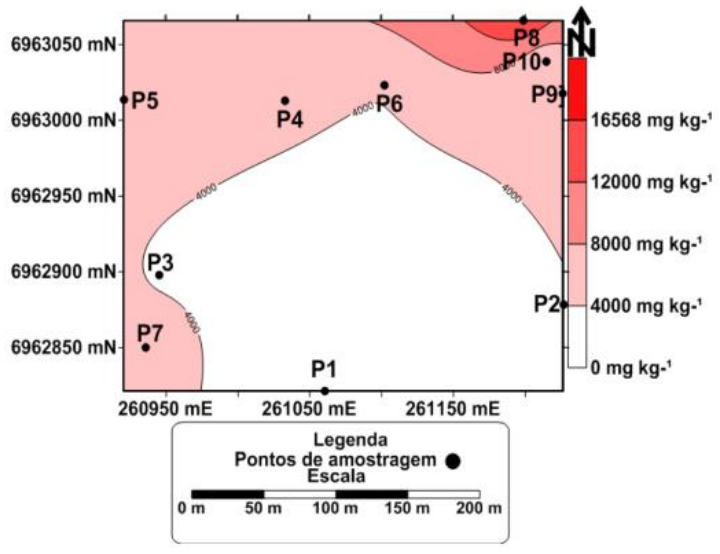

(b)

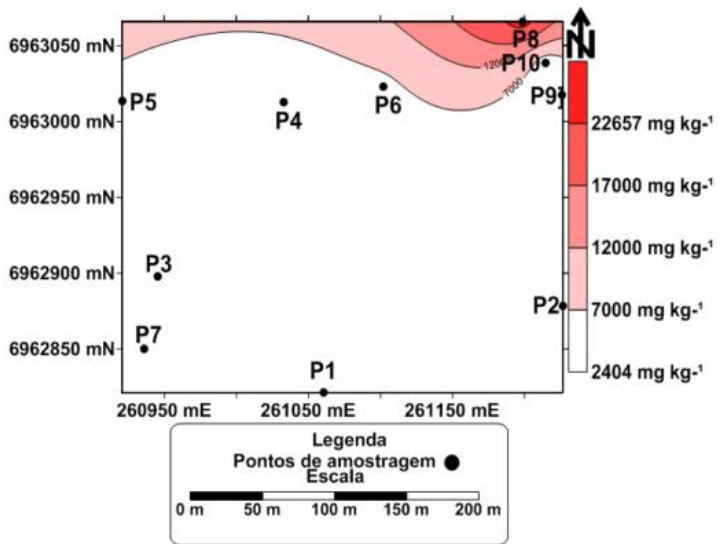

(c)

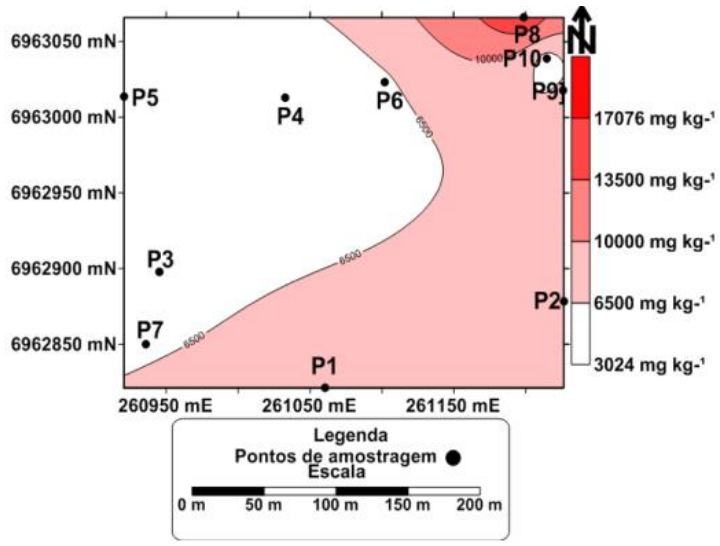

(d)

rigura J. Loncentraçoes ae barıo nas prorunaıaaaes ae $u(a), 50$ (b), 100 (c) a $150 \mathrm{~cm}$ (d), Seberi - RS, 2011. 
$\mathrm{Na}$ profundidade $0 \mathrm{~cm}$ (figura $3 \mathrm{a}$ ), o maior valor ocorreu no P7 $\left(20580,99 \mathrm{mg} \mathrm{kg}^{-1}\right)$, já o menor ocorreu no P1, onde a concentração foi menor que o Limite de Detecção (L.D.). Na profundidade de $50 \mathrm{~cm}$ (figura 3b), o maior valor encontrado foi de 16567,11 $\mathrm{mg} \mathrm{kg}^{-1}$ (P8), já o menor encontra-se no P1 (menor que o L.D.). Em $100 \mathrm{~cm}$ (figura 3c), o maior valor foi de $25656,02 \mathrm{mg} \mathrm{kg}^{-1}$ (P8) e o menor de 2404,21 mg $\mathrm{kg}^{-1}(\mathrm{P} 2)$. Na profundidade de $150 \mathrm{~cm}$ (figura 3d), o maior valor esteve presente no P8 $\left(17075,06 \mathrm{mg} \mathrm{kg}^{-1}\right)$ e o menor esteve no P4 $\left(3024,92 \mathrm{mg} \mathrm{kg}^{-1}\right)$. Como pode ser observado, as maiores concentrações do elemento estão presentes nas regiões de menor cota topográfica, evidenciando a relacão com o fluxo superficial da água.
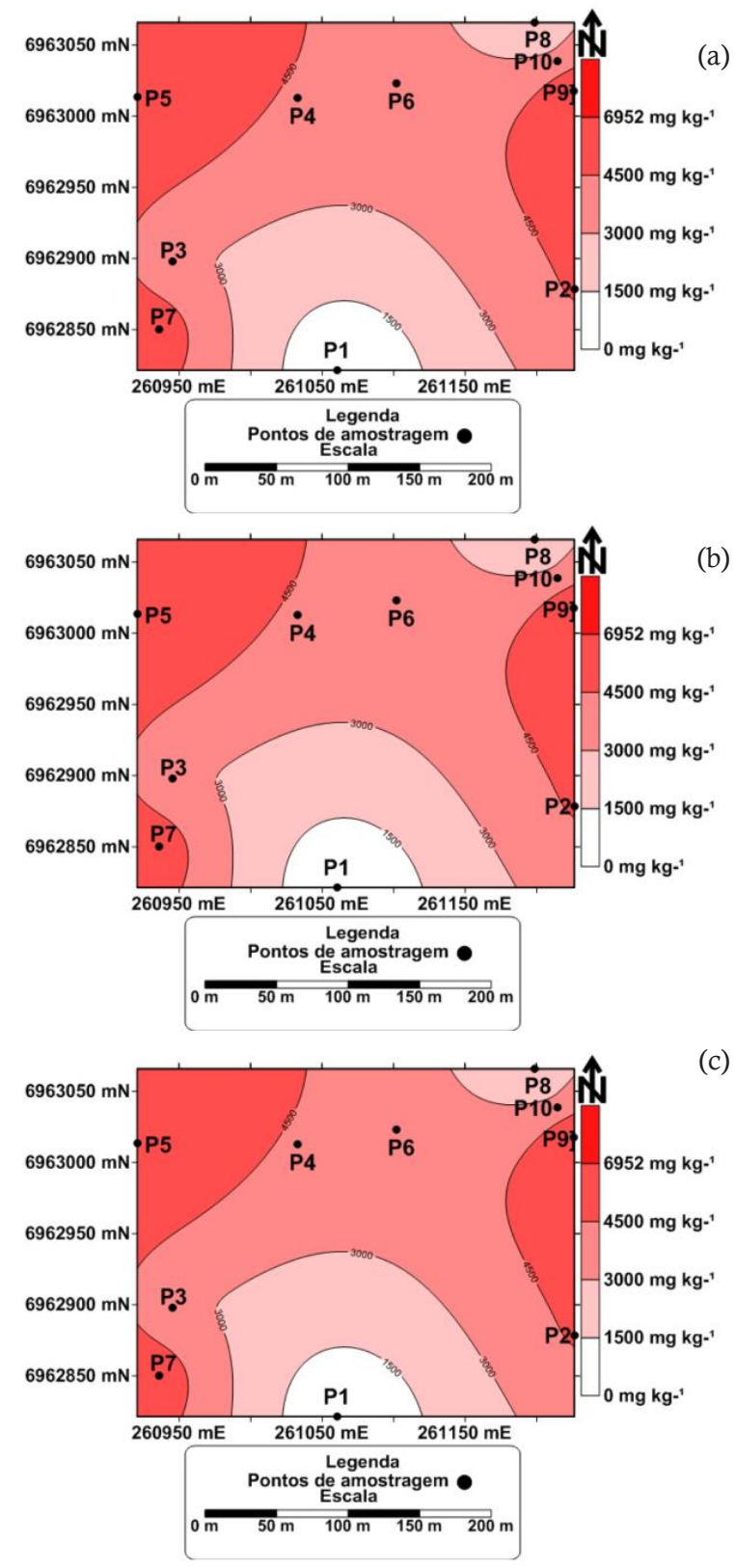

Figura 4. Concentrações de Bário nas profundidades de 200 (e), 250 (f) e 300 cm (g), Seberi - RS, 2011.
A figura 4 ilustra a concentração de Ba total nas profundidades de 200 a $300 \mathrm{~cm}$, onde a maior concentração esteve presente no P8 (18643,58 $\left.\mathrm{mg} \mathrm{kg}^{-1}\right)$, em $250 \mathrm{~cm}$, e as menores nos pontos $\mathrm{P} 1, \mathrm{em} 200 \mathrm{~cm}$, e P2 em 250 e $300 \mathrm{~cm}$, onde as concentrações foram menores que o L.D. Em $200 \mathrm{~cm}$ (figura 4e) o maior valor encontrado foi no P5 $\left(6006,10 \mathrm{mg} \mathrm{kg}^{-1}\right)$ e o menor ocorreu no P1 (menor que o L.D.). Nas profundidades de 250 (figura $4 \mathrm{f}$ ) e $300 \mathrm{~cm}$ (figura $4 \mathrm{~g}$ ) os maiores valores estiveram presentes no P8 (18643,58 e 17812,06 $\mathrm{mg} \mathrm{kg}^{-1}$, respectivamente), já os menores valores foram encontrados para as duas profundidades no $\mathrm{P} 2$ (menor que o L.D.) em $50 \mathrm{~cm}$. Com análise do comportamento do elemento $\mathrm{Ba}$, na área ocupada pelo aterro, é possível afirmar que em todas as profundidades a concentração do elemento aumenta nas cotas mais baixas do terreno, indicando relação com o fluxo superficial da água.

A maior concentração observada nos 10 pontos de amostragem ocorreu no ponto 8 , na profundidade de $100 \mathrm{~cm}\left(25656,01 \mathrm{mg} \mathrm{kg}^{-1}\right)$, e os menores valores foram nos pontos onde a concentração foi menor que o L.D. (P1 de 200 a $300 \mathrm{~cm}$ e P2 de 0 a $50 \mathrm{~cm}$ ).

A figura 5 a ilustra a variação da concentração de bário nas profundidades de 0 a $300 \mathrm{~cm}$ (figura $5 \mathrm{a}$ ) e nos 10 diferentes pontos (figura $5 b$ ).
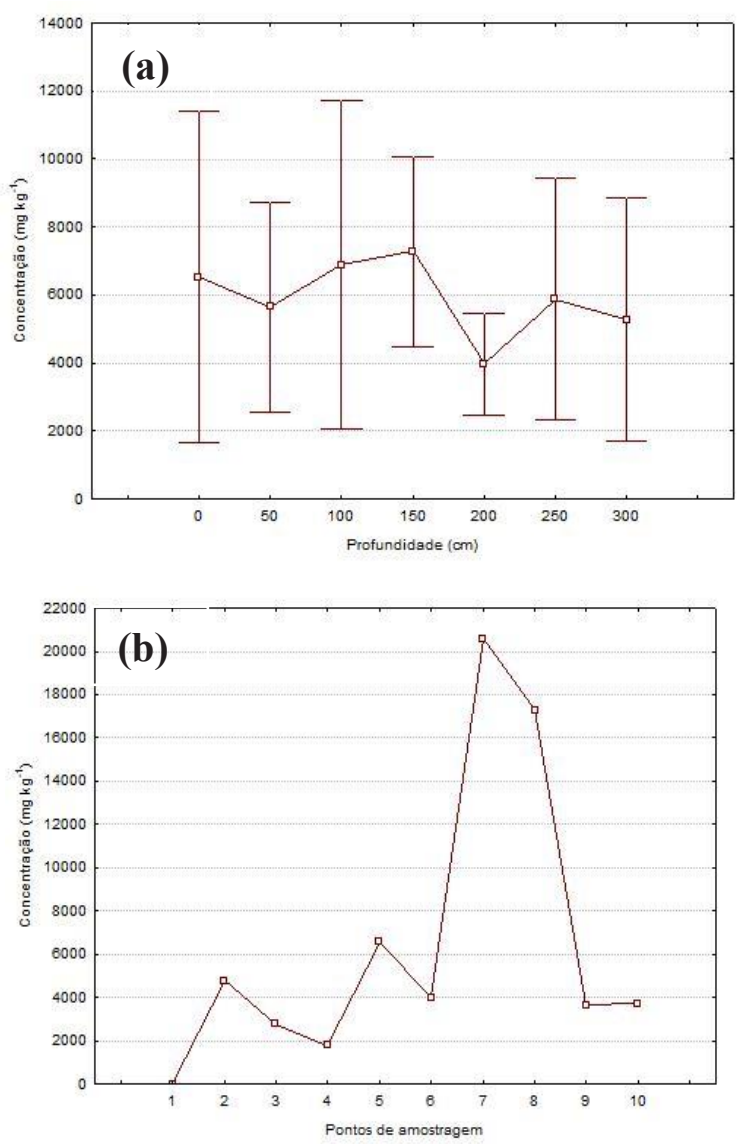

Figura 5. Variação da concentração de Bário nas diferentes profundidades (a) e pontos de amostragem (b). 
Como pode ser observado na figura $5 \mathrm{a}$, as maiores concentrações de bário ocorreram na profundidade de $100 \mathrm{~cm}$. Com relação aos pontos de amostragem, as maiores concentrações ocorreram no P7 e as menores no P1, evidenciando a relação com o fluxo superficial da água. Em relação à legislação vigente, os valores que foram menores que o VMP estiveram presentes nas profundidades de 200, 250 e 300 nos pontos $\mathrm{P} 1, \mathrm{P} 2$ e $\mathrm{P} 1$, respectivamente (os demais pontos excederam o valore permitido pela CONA 420/2009), evidenciando que as menores concentrações estão presentes em regiões mais elevadas.

\subsection{Cobre $(\mathrm{Cu})$}

A resolução CONAMA $\mathrm{N}^{\circ}$ 420/2009 estabelece a concentração limite de $60 \mathrm{mg} \mathrm{kg}^{-1}$ para o elemento $\mathrm{Cu}$ em solos. Crianças alimentadas, exclusivamente, à base de leite de vaca estão mais propensas a desenvolver deficiência de cobre que as crianças alimentadas com leite materno, pelo pobre conteúdo de cobre no leite de vaca, devido à absorção limitada deste mineral neste tipo de leite, sendo apenas $15 \%$ do cobre absorvido (BARCELOS, 2008).

Quando presente em altas concentrações, o cobre pode causar danos ao fígado, aos rins e ao cérebro. Entropicamente, origina-se de efluentes de metalurgias,

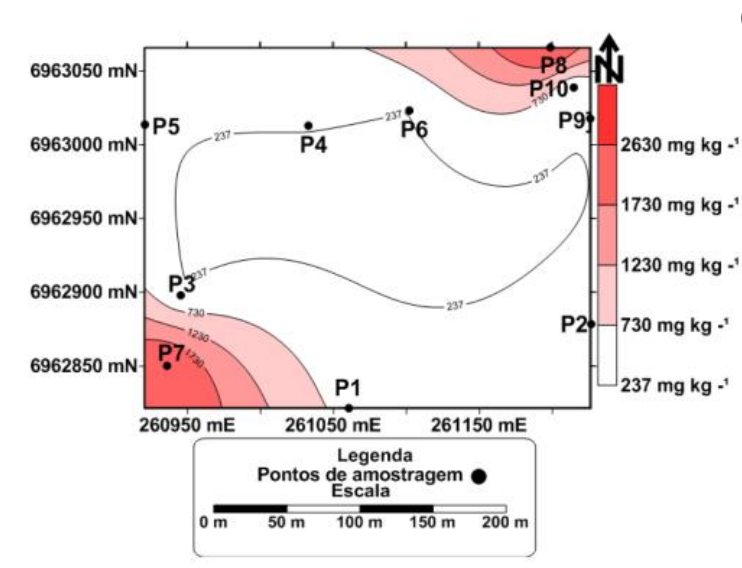

(a)

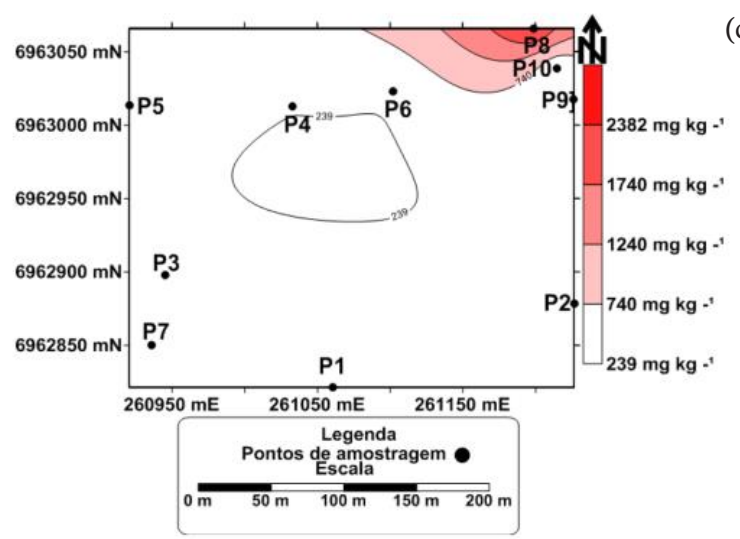

(c) da mineração, de inseticidas e fungicidas (CUNHA \& MACHADO, 2004).

A figura 6 apresenta as concentrações de cobre total na área de estudo nos pontos P1 a P10, nas profundidades $0,50,100$ e $150 \mathrm{~cm}$, onde o maior valor observado esteve presente na amostra superficial do P8 (2630,90 $\left.\mathrm{mg} \mathrm{kg}^{-1}\right)$, já o menor esteve na profundidade de $150 \mathrm{~cm}$ no P10 (232,45 mg kg$\left.{ }^{-1}\right)$. Na amostra superficial (figura 6a), o maior valor ocorreu no P8 $(2630,90 \mathrm{mg}$ $\left.\mathrm{kg}^{-1}\right)$, já o menor esteve presente no P10 (237,18 $\left.\mathrm{mg} \mathrm{kg}^{-1}\right)$. $\mathrm{Na}$ profundidade de $50 \mathrm{~cm}$ (figura $6 \mathrm{~b}$ ), o maior valor encontrado foi no P8 $\left(2448,15 \mathrm{mg} \mathrm{kg}^{-1}\right)$ e o menor foi no P7 (251,42 $\left.\mathrm{mg} \mathrm{kg}^{-1}\right)$. Em $100 \mathrm{~cm}$ (figura 6c) o maior valor esteve presente no P8 (2381,67 $\left.\mathrm{mg} \mathrm{kg}^{-1}\right)$ e o menor esteve no P7 $\left(239,42 \mathrm{mg} \mathrm{kg}^{-1}\right)$. Na profundidade de 150 cm (figura 6d), a maior concentração foi de 2378,10 $\mathrm{mg} \mathrm{kg}^{-1}$ (P8) e a menor de 232,45 (P10). Com a análise das profundidades de 0 a $150 \mathrm{~cm}$, foi possível perceber que os maiores valores estão presentes no $\mathrm{P} 8 \mathrm{em}$ todas as profundidades.

A figura 7 mostra a concentração de cobre total nas profundidades de 200 a $300 \mathrm{~cm}$, onde a maior concentração foi observada em $250 \mathrm{~cm}$ no P8 (2500,60 $\left.\mathrm{mg} \mathrm{kg}{ }^{-1}\right)$ e a menor em $300 \mathrm{~cm}$ no P7 (155,30 $\left.\mathrm{mg} \mathrm{kg}^{-1}\right)$. $\mathrm{Na}$ profundidade de $200 \mathrm{~cm}$ (figura 7e), o maior valor ocorreu no P8 (2318,55 $\left.\mathrm{mg} \mathrm{kg}^{-1}\right)$ e o menor ocorreu no
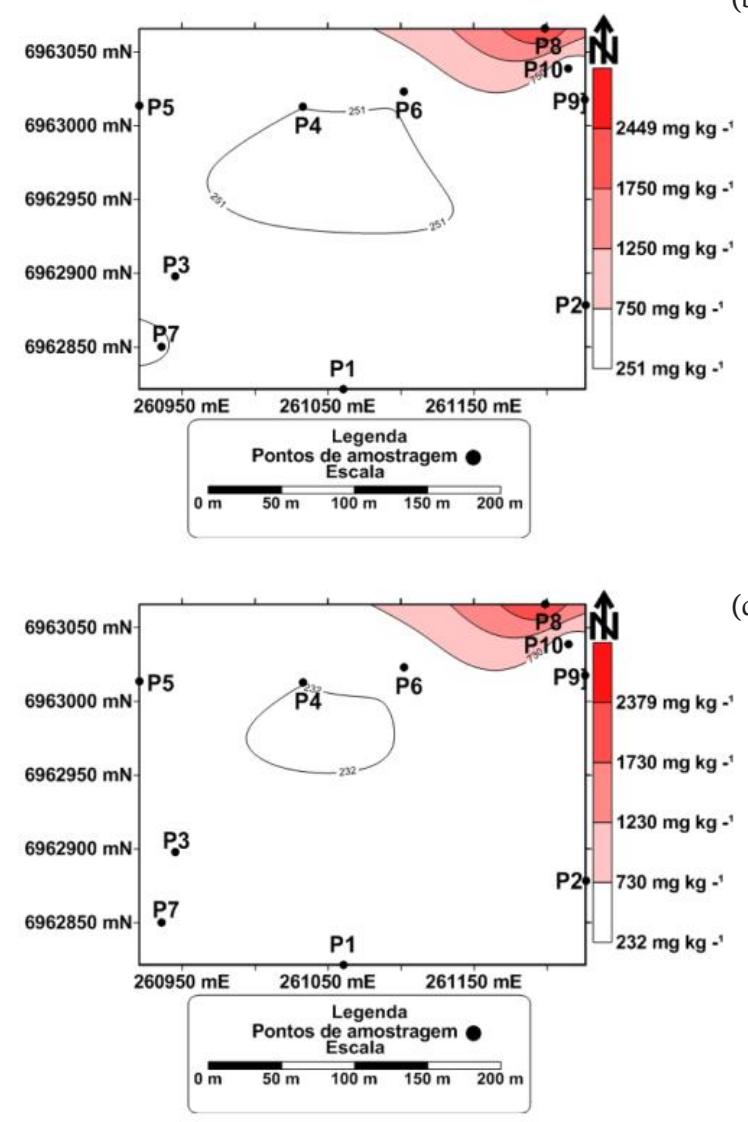

Figura 6. Concentrações de Cobre nas profundidades de 0 (a), 50 (b), 100 (c) a 150 cm (d), Seberi - RS, 2011. 

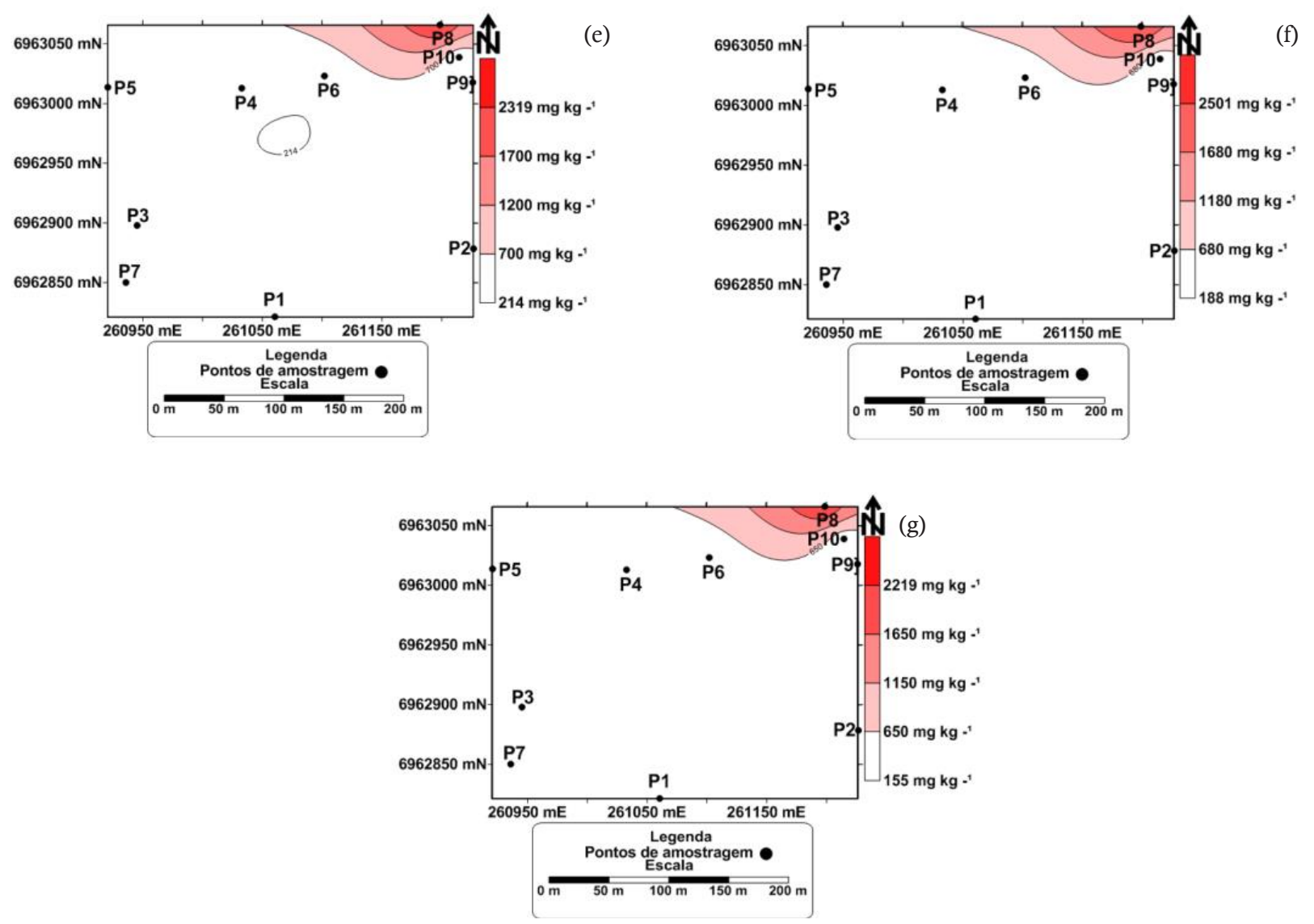

Figura 7. Concentrações de Cobre nas profundidades de 200 (e), 250 (f) a 300 cm (g), Seberi - RS, 2011.

P3 (214,79 $\left.\mathrm{mg} \mathrm{kg}^{-1}\right)$. Na profundidade de $250 \mathrm{~cm}$ (figura 7f) o maior valor foi de $2500,60 \mathrm{mg} \mathrm{kg}^{-1}$ (P8) e o menor foi de $188,04 \mathrm{mg} \mathrm{kg}^{-1}$ (P7), já na profundidade de 300 cm (figura $7 \mathrm{~g}$ ) o maior valor foi de $2218,81 \mathrm{mg} \mathrm{kg}^{-1}$ ) (P8) e o menor foi de $155,30 \mathrm{mg} \mathrm{kg}^{-1}$ (P7).

Após análise da concentração do elemento $\mathrm{Cu}$ nas profundidades de 200 a $300 \mathrm{~cm}$ foi possível identificar que as concentrações mais elevadas estão presentes nas cotas mais baixas do terreno, indicando a relação com o fluxo superficial, também é possível identificar que em todos os pontos as concentrações excederam o VMP.

A figura 8 ilustra a variação da concentração de cobre nas profundidades de 0 a $300 \mathrm{~cm}$ (figura 8a) e nos 10 pontos $(8 b)$.

Como pode ser observado na figura $8 \mathrm{a}$, as maiores concentrações de cobre estiveram presentes na amostra superficial, em relação aos pontos de amostragem (figura 8b), as maiores concentrações estiveram presentes no P8, evidenciando a relação com o fluxo superficial da água.
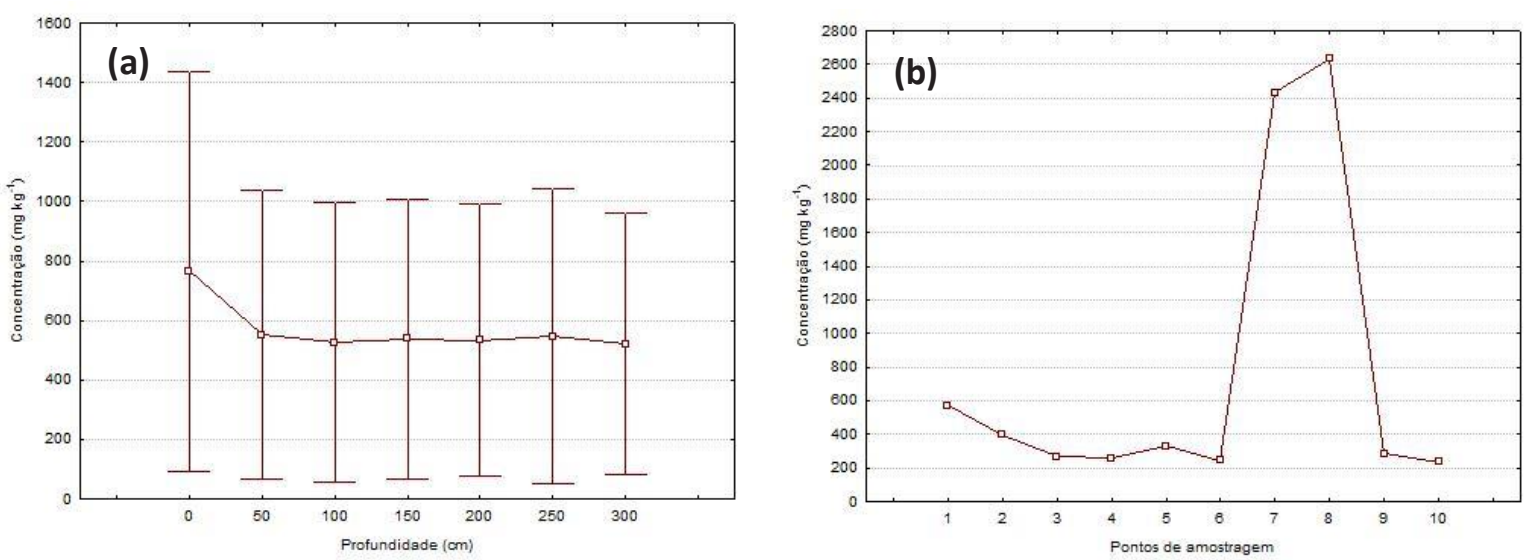

Figura 8. Variação da concentração de Cobre nas diferentes profundidades (a) e pontos de amostragem (b). 


\subsection{Cromo $(\mathrm{Cr})$}

Para CUNHA (2004), o Cr é um elemento indispensável para o metabolismo dos açúcares, a sua deficiência no organismo humano pode levar à neuropatia periférica e à diabetes; porém, o cromo hexavalente em altas concentrações na água pode causar câncer.

A concentração de cromo em solos pode variar de acordo com as normas estabelecidas para cada país em especifico, podendo variar muito, como exemplo disto podemos citar a Alemanha, onde a concentração de cromo no solo é de $125 \mathrm{mg} \mathrm{kg}^{-1}$, enquanto que na França é $250 \mathrm{mg} \mathrm{kg}^{-1}$, como afirma TSUTIYA (1999).

A figura 9 apresenta a variação da concentração de Cr total na área de estudo, nos 10 pontos de amostragem nas profundidades, variando de 0 a 150 $\mathrm{cm}$, onde o maior valor esteve presente na profundidade de $150 \mathrm{~cm}$ no P8 (531,92 $\left.\mathrm{mg} \mathrm{kg}^{-1}\right)$ e menor em 50 $\mathrm{cm}$ no P5 (50,35 $\left.\mathrm{mg} \mathrm{kg}^{-1}\right)$. Nas amostras superficiais (figura 9a), o maior valor encontrado foi de $508,99 \mathrm{mg}$ $\mathrm{kg}^{-1}$ (P8) e o menor ocorreu no P5 $\left(60,80 \mathrm{mg} \mathrm{kg}^{-1}\right)$. Na profundidade de $50 \mathrm{~cm}$ (figura $9 \mathrm{~b}$ ), o maior valor foi de 527,89 $\mathrm{mg} \mathrm{kg}^{-1}$ (P8) e o menor foi de 50,35 (P4), já em $100 \mathrm{~cm}$ (figura 9c) o maior valor foi identificado

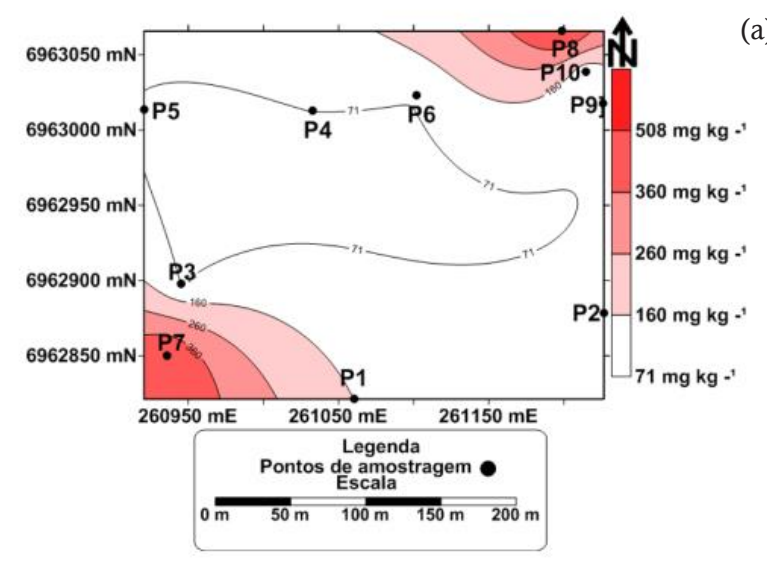

(b)

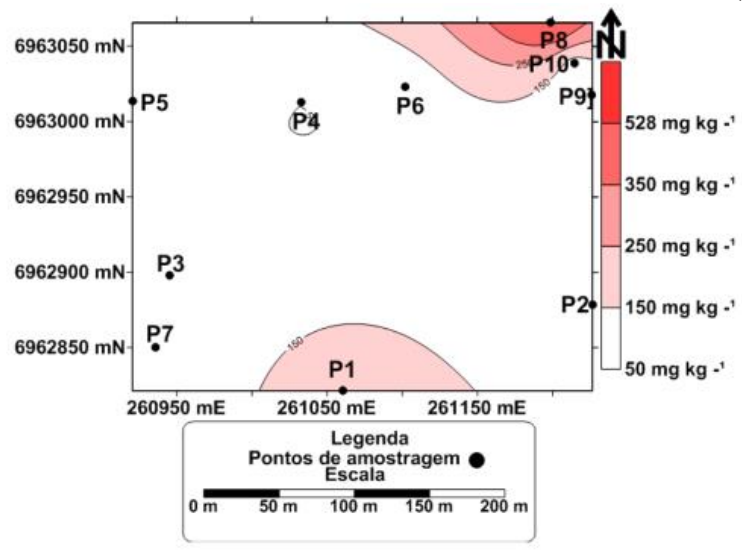

Figura 9. Concentrações de Cromo nas profundidades de 0 (a), 50 (b), cm Seberi - RS, 2011.

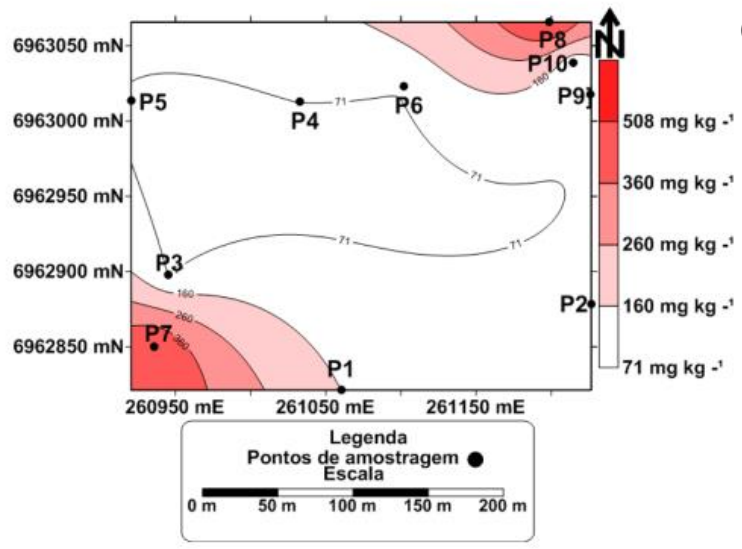

(c)

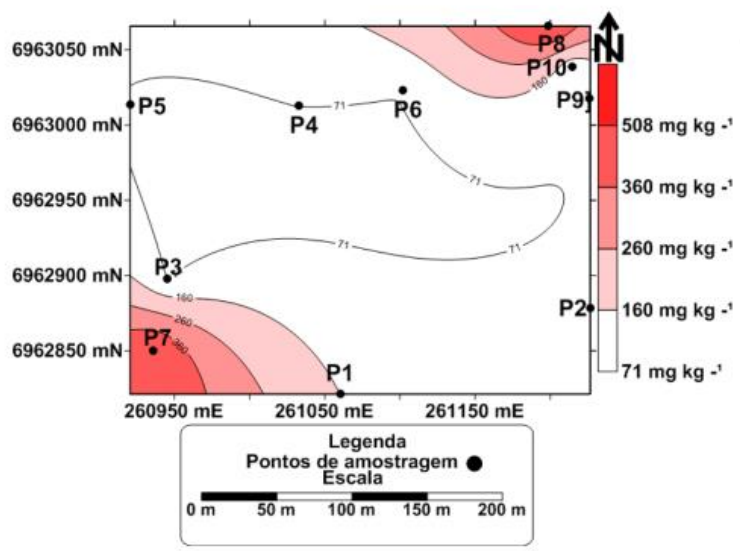

(d)

Figura 9. Continuação....Concentrações de Cromo nas profundidades de 100 (c) a 150 (d) cm Seberi - RS, 2011.

no P8 (476,63 $\left.\mathrm{mg} \mathrm{kg}^{-1}\right)$ e o menor foi no P5 (59,07 mg $\mathrm{kg}^{-1}$ ). Nas amostras realizadas a $150 \mathrm{~cm}$ (figura 9d), o maior valor encontrado foi de $531,92 \mathrm{mg} \mathrm{kg}^{-1}$ (P8) e o menor de $71,42 \mathrm{mg} \mathrm{kg}^{-1}$ (P5). Nas profundidades analisadas $(0 \mathrm{a} 150 \mathrm{~cm})$ apenas nos pontos $\mathrm{P} 3(0$ e 100 $\mathrm{cm}), \mathrm{P} 4$ (0 e $50 \mathrm{~cm}), \mathrm{P} 5(0,50,100$ e $150 \mathrm{~cm})$ e P6 (50 e $100 \mathrm{~cm}$ ), os valores não ultrapassaram o VMP proposto pela CONAMA 420/2009, a qual considera o valor de prevenção de $\mathrm{Cr}$ no solo de $75 \mathrm{mg} \mathrm{kg}^{-1}$.

A figura 10 apresenta a variação da concentração de $\mathrm{Cr}$ total nas profundidades de 200 (figura 10e), 250 (figura 10f) e $300 \mathrm{~cm}$ (figura $10 \mathrm{~g}$ ), onde a maior concentração ocorreu na profundidade de 200 cm no P8 (9522,50 $\left.\mathrm{mg} \mathrm{kg}^{-1}\right)$ e a menor ocorreu em 300 $\mathrm{cm}$ no P6 $\left(54,75 \mathrm{mg} \mathrm{kg}^{-1}\right)$. Para as profundidades de 200, 250 e $300 \mathrm{~cm}$ os maiores valores ocorreram no P8 (522,50 mg kg${ }^{-1}, 467,08 \mathrm{mg} \mathrm{kg}^{-1}$ e 463,37 $\mathrm{mg} \mathrm{kg}^{-1}$ respectivamente) e as menores ocorreram nos pontos P3 (72,99 $\left.\mathrm{mg} \mathrm{kg}^{-1}\right)$, P4 (74,69 $\left.\mathrm{mg} \mathrm{kg}^{-1}\right)$ e P6 (54,75 mg $\left.\mathrm{kg}^{-1}\right)$ respectivamente. Com base na legislação vigente (CONAMA 420/2009) no P3 (200 cm), P4 (250 e 300 $\mathrm{cm})$ P6 e P9 $(300 \mathrm{~cm})$ apresentaram concentrações inferiores ao VMP. 


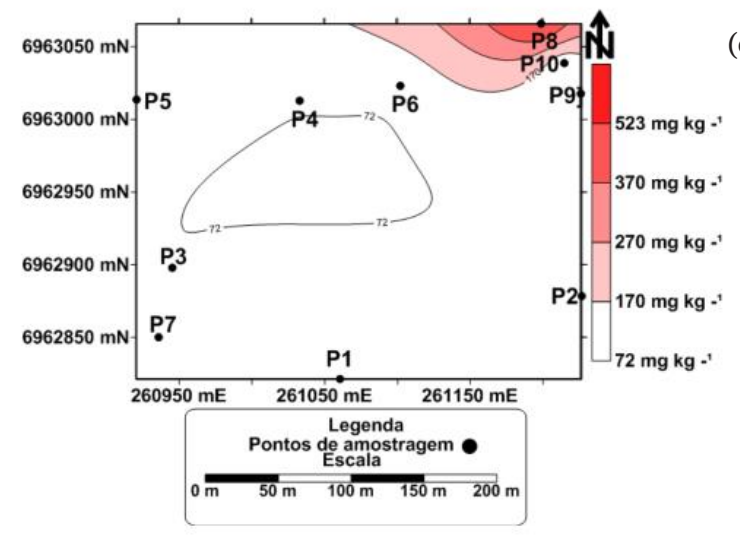

(e)
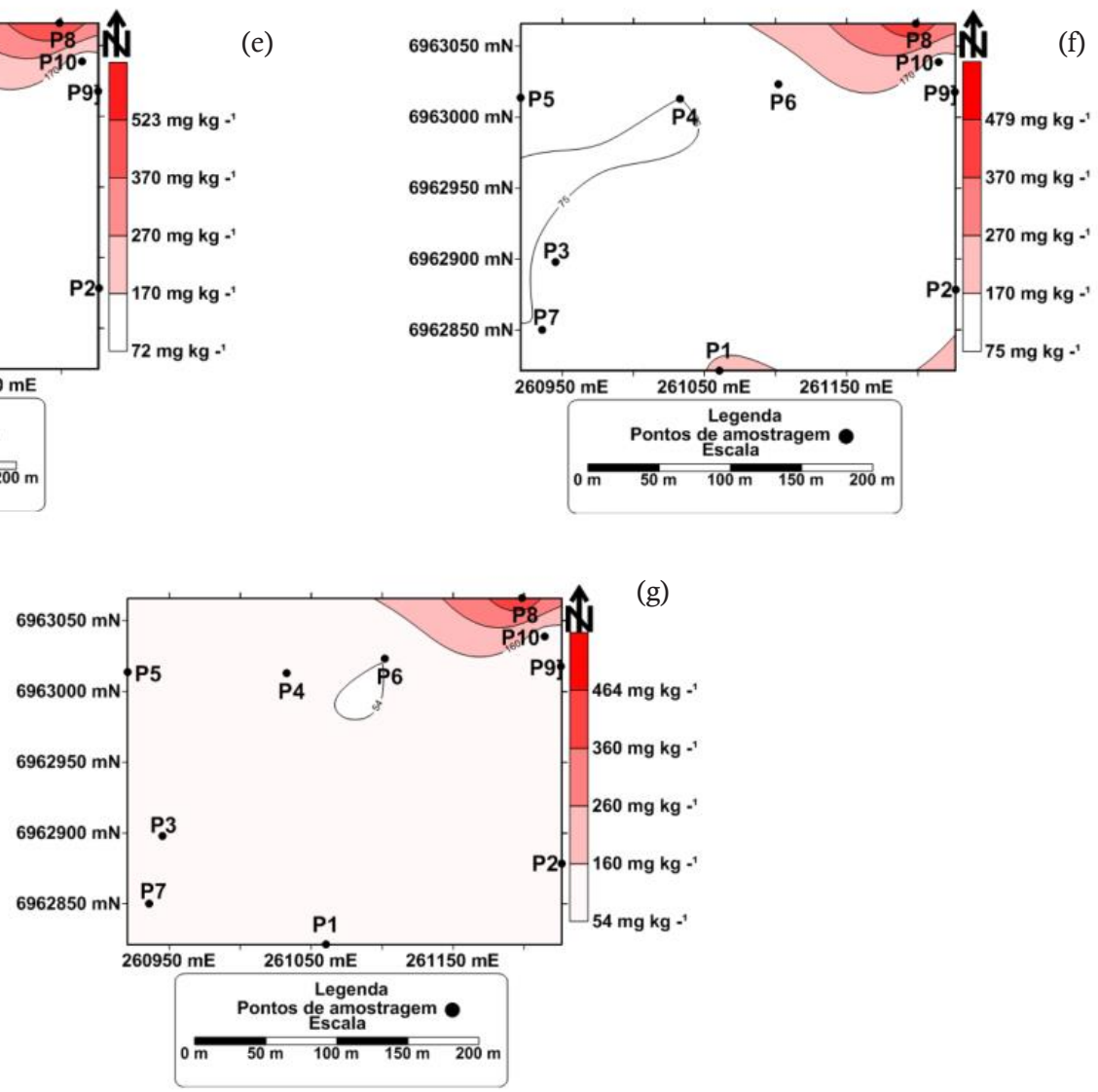

Figura 10. Concentração de Cromo nas profundidades de 200 (e), 250 (f) a 300 (g) cm Seberi - RS 2011.
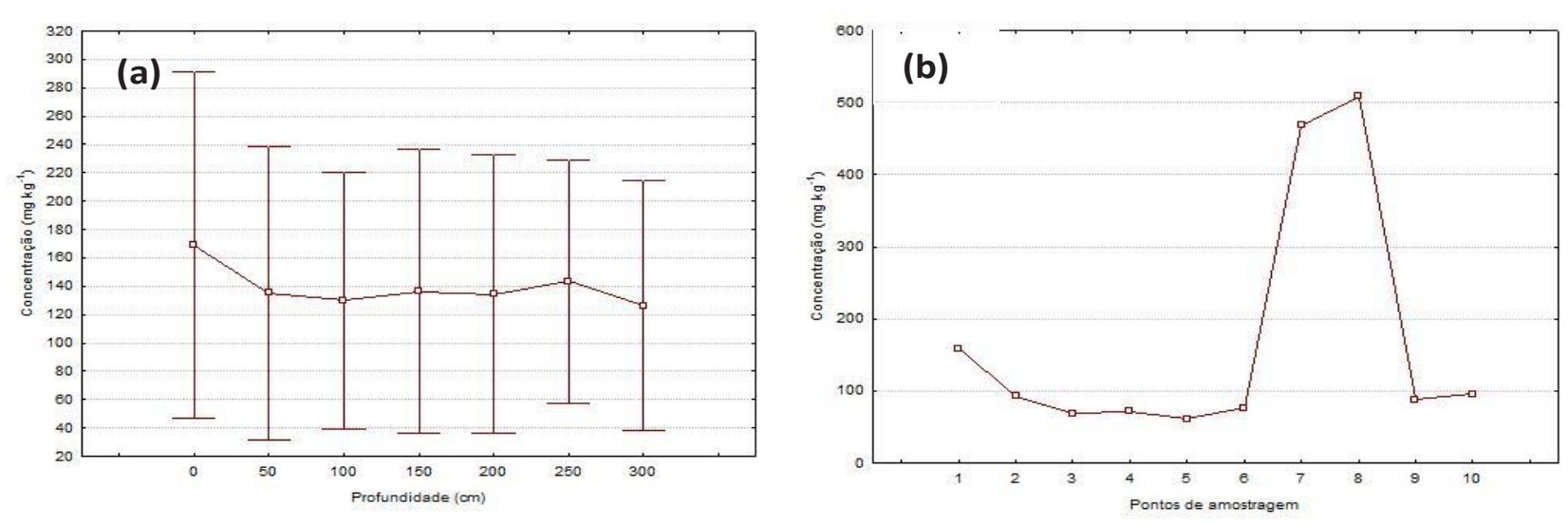

Figura 11. Variação da concentração de Cromo nas diferentes profundidades (a) e pontos de amostragem (b).

A figura 11 ilustra a concentração de cromo nas 7 diferentes profundidades (figura 11a) e nos 10 pontos de amostragem (11b).

Como pode ser observado na figura 11 , as maiores concentrações de cromo ocorreram na amostra superficial, em relação aos pontos de amostragem, as maiores concentrações estiveram presentes no P8, evidenciando a relação com o fluxo superficial da água.

\subsection{Correlação entre os parâmetros}

A tabela 2 ilustra a correlação entre os parâmetros analisados, sendo os valores destacados na cor vermelha apresenta correlação.

Como pode ser observado na tabela acima, o elemento bário apresentou correlação inversa com a altitude, evidenciando que os maiores valores estão presentes nas regiões mais baixas da área de estudo. 
Tabela 2. Correlação estatística entre os parâmetros analisados

\begin{tabular}{lcccc}
\hline & Altitude & Ba & Cu & Cr \\
\hline Altitude & 1 & & & \\
Ba & $-0,26$ & 1 & & \\
$\mathbf{C u}$ & $-0,18$ & 0,80 & 1 & 1 \\
$\mathbf{C r}$ & $-0,18$ & 0,74 & 0,99 & \\
\hline
\end{tabular}

O elemento cobre apresentou correlação positiva com o elemento bário e o elemento cromo, indicando a relação entre esses dois elementos na área de estudo.

\section{CONCLUSÃO}

Os metais pesados Bário, Cobre e Cromo apresentaram concentrações indicando contaminação do solo em todos os pontos amostrados. Houve, também, variação da concentração dos elementos em função da profundidade. Foi possível identificar a relação fluxo superficial da água com a concentração dos metais, principalmente no P8, onde, principalmente, os elementos Cobre e Cromo apresentaram as maiores concentrações.

\section{REFERÊNCIAS}

ALENCAR, M. M. M. Reciclagem de Lixo numa Escola Pública do Município de Salvador. Candombá, Vol. 1, n.2, p. 96 - 113, 2005.

BARCELOS, T. D. de J. Cobre: Vital ou Prejudicial para a Saúde Humana? Covilhão. 2008. 70f. Dissertação (Mestrado em Ciências da Saúde) - Faculdade de Ciências da Saúde, Universidade da Beira Interior, Cavilhã, 2008.

BONA, I. A. T.; SARKIS, J. E. S.; SALVADOR, V. L. R. Análise Arqueométrica de Cerâmica Tupiguarani da Região Central do Estado do Rio Grande do Sul, Brasil, Usando Fluorescência de Raios X por Dispersão de Energia (EDXRF). Revista Química Nova, Vol.30, p.785-790, 2007.

CUNHA, G. F.; MACHADO, J. G. Estudos de Geoquímica Ambiental e o Impacto na Saúde Pública no Município de São Gonçalo do Piauí, Estado do Piauí. Programa Nacional de Pesquisa em Geoquímica Ambiental e Geologia Médica (PGAGEM). CPRM - Serviço Geológico Do Brasil 2004. Disponível em: http://www.cprm.gov.br/gestao/estudo_ geoq_amb.pdf. Acessado em: 4 de Agosto de 2012.

GARCILASSO, V.P.; VELÁZQUEZ, S. M. S. G.;
COELHO, S. T. Geração de energia elétrica a partir do biogás proveniente de aterro sanitário - Estudo de Caso. XIII CONGRESSO BRASILEIRO DE ENERGIA, 2010. Anais eletrônicos... Rio de Janeiro: UFRJ, 2010. Disponível em: http://cenbio. iee.usp.br/download/publicacoes/xiiicbe_aterro.pdf. Acessado em: 4 de Agosto de 2012.

HIRATA, A. C. R. Os Recursos Hídricos Subterrâneos e as Novas Exigências Ambientais. Revista IG, Vol.14, n.1, p.39-62, 1993.

KEMERICH, P. D. C.; BORBA, W. F.; SILVA, R. F.; BARROS, G.; GERHARDT, A. E.; FLORES, C. E. B. Valores anômalos de metais pesados em solo de cemitério. Revista Ambi-Agua, Vol. 7, p. 140-156, 2012.

MORAIS, J. L. de; SIRTORI, C.; ZAMORA, P. P. Tratamento de chorume de aterro sanitário por foto catálise heterogênea integrada a processo biológico convencional. Revista Química Nova, Vol. 29, p. 20-23, 2006.

PATACA, L. C.; BORTOLETO, G. G.; BUENO, M. I. M. S. Determinação de arsênio em águas contaminadas usando fluorescência de raios-X por energia dispersiva. Revista Química Nova, Vol.28, n.4, p. 579-582, 2005.

RANNO, S. K.; RHODEN, A. C.; SILVA, L. S.; MALLMANN, F. J. K.; CAMPONOGARA, M. S. Calagem em solos de várzea: Liberação de ferro e produtividade do arroz irrigado. FERTBIO 200. Anais eletrônicos... Lages: FERTBIO, 2004. Disponível em: http://coralx.ufsm.br/ppgcs/congressos/ Fertbio2004/Fs174.pdf. Acessado em: 4 de Agosto de 2012.

TARTARI, L. C. Avaliação do Processo de Tratamento do Chorume de Aterro Sanitário de Novo Hamburgo. Revista Liberato, Vol. 6, n. 6, p. 66-74, 2005.

TSUTIYA, M. T. Metais pesados: o principal fator limitante para o uso agrícola de biossólidos das esta- 
ções de tratamento de esgoto. In: XX CONGRESSO BRASILEIRO DE ENGENHARIA SANITÁRIA E AMBIENTAL, 1999, Rio de Janeiro. Anais... Rio de Janeiro: ABES, 1999.

WASTOWSKI A. D.; DA ROSA G. M.; CHERUBIN M. R.; RIGO J. P G. Caracterização dos Níveis de Elementos Químicos Em Solo, Submetido a Diferentes Sistemas de Uso E Manejo, Utilizando Espectrometria de Fluorescência de Raios-X Por Energia Dispersiva (EDXRF). Revista Química Nova. Vol.33, n.7. p.1449-1452, 2010. 